\title{
Polioencefalomalácia em caprinos: oito relatos de caso
}

Laís Resende Paulino[a]", Nivan Antônio Alves da Silva ${ }^{[b]}$, Rodolfo José Cavalcanti Souto ${ }^{[b]}$, Maria Isabel de Souza ${ }^{[b]}$, Nivaldo de Azevedo Costa ${ }^{[b]}$, Luiz Teles Coutinho ${ }^{[b]}$ Carla Lopes de Mendonçç ${ }^{[b]}$, José Augusto Bastos Afonso[b], Jobson Filipe de Paula Cajueiro[b]

\footnotetext{
[a] Programa de Residência em Sanidade de Ruminantes, Clínica de Bovinos, Universidade Federal Rural de Pernambuco (UFRPE), Garanhuns, PE, Brasil

[b] Clínica de Bovinos, Universidade Federal Rural de Pernambuco (UFRPE), Garanhuns, PE, Brasil
}

*Autor correspondente

e-mail: lalapaulino@gmail.com

\section{Resumo}

A polioencefalomalácia (PEM) ou necrose cerebrocortical é a denominação para a lesão que resulta em amolecimento e necrose da substância cinzenta cerebrocortical. A etiologia é comumente associada à redução da disponibilidade de tiamina para o ruminante, como consequência da redução da sua síntese ou elevada atividade da tiaminase no rúmen. É associada também a outras causas: enxofre e sulfatos em excesso, deficiência de cobalto, intoxicação por chumbo, privação de água com consequente intoxicação por sódio e infecção por HVB-5. Oito caprinos, sendo sete fêmeas e um macho, com idades entre 3 meses e 2 anos e meio foram atendidos na Clínica de Bovinos, Campus Garanhuns - UFRPE, nos anos de 2015 e 2016. Na anamnese foi relatado que os animais apresentavam sinais neurológicos e, em dois casos, havia outros animais acometidos no rebanho. Todos os animais recebiam concentrado na dieta e dois destes haviam passado recentemente por mudança no manejo alimentar. Ao exame clínico geral apresentavam-se em estação ou, de acordo com a gravidade, em decúbito lateral/esterno-lateral, apáticos, excicose variando entre 5 e 10\%, apetite ausente ou caprichoso. No exame neurológico, as principais lesões foram no cérebro, tronco encefálico e cerebelo, com sinais clínicos variados: redução ou ausência da acuidade visual, ausência de reflexo pupilar e palpebral, nistagmo, opstótomo, andar em círculos, pressão de cabeça contra objetos, movimentos de pedalagem, teste labirinto propioceptivo positivo, redução do tônus lingual e bruxismo. À avaliação hematológica, quatro animais apresentaram leucocitose, três por neutrofilia e um por linfocitose, e destes, três apresentaram hiperfibrinogenemia e um hipopreteinemia. Diante da epidemiologia e dos achados clínicos, suspeitou-se de PEM; portanto, foi estabelecido o protocolo de tratamento com dexametasona (0,2 mg/kg), cloridrato de tiamina (10-20 mg/kg), transfaunação e, de acordo com a necessidade, hidratação, 
antibióticos e antiparasitários. Os animais apresentaram melhora clínica a partir do $2^{\circ}$ dia de tratamento e houve uma variação em relação ao tempo de resposta dos sinais neurológicos. Todos os caprinos receberam alta após o término do tratamento, porém quatro destes ainda apresentavam redução da acuidade visual. No período estudado foram atendidos 121 caprinos, dos quais 16 (13,2\%) foram acometidos por doenças neurológicas, logo, 50\% das neuropatias corresponderam à PEM. As mudanças no manejo alimentar ou o excesso de concentrado na dieta, aparentemente, foram os fatores determinantes para o surgimento dos casos. Dietas ricas em carboidratos favorecem a elevação de tiaminases, resultando em um desequilíbrio e redução da disponibilidade de tiamina para o animal. As alterações na dieta constituem um dos principais problemas associados aos casos de PEM, no entanto, a etiologia exata é difícil de determinar. A fim de prevenir a ocorrência de novos casos, faz-se necessária uma análise das possíveis causas desta enfermidade através do histórico do manejo do rebanho. 